\title{
Translation Elongation Factors: are Useful Biomarkers in Cancer?
}

\section{Cristiano Luigi*}

Prestige Lab, Prestige Company, Loro Ciuffenna (AR), Italy

*Corresponding author: Cristiano Luigi, Prestige Lab, Prestige Company, Loro Ciuffenna (AR), Italy

\section{Abstract}

The Eukaryotic Translation Elongation Factors are a large protein family involved in the elongation step of eukaryotic translation but it has also various moonlight functions inside the cell both in normal and in pathological conditions. The proteins included in this family are EEF1A1, EEF1A2, EEF1B2, EEF1D, EEF1G, EEF1E1, enclosed their various isoforms, i.e. PTI-1, CCS-3, HD-CL-08, and MBI-eEF1A. They are proteins all bound to cancer development and progression and show gene amplification, genomic rearrangements, and alteration of expression levels in many kinds of cancers. These abnormalities have undoubtedly repercussions on cellular biology and cellular behaviour in the various step of transformation and progression of cancer but surely should be considered also for the enhancement of invasiveness and for the metastasis. Thus, the Eukaryotic Translation Elongation Factors may possibly useful biomarkers for human cancers although more studies are needed to better elucidate their exact contribution as diagnostic, prognostic, and progression markers

Keywords: Eukaryotic translation elongation factors; translation; cancer; biomarker; EEF1A1; EEF1A2; EEF1B2; EEF1D; EEF1G; EEF1E1; EEF1H; PTI-1; EEF1A1L14; CCS-3; MBI-eEF1A; HD-CL-08

\section{Background}

Translation is one of the most important biological processes that take place into the cell because it permits genetic information to become functional proteins. It is formally divided into three main processes between them consequential: an initiation step, an elongation step, and a termination step. The Eukaryotic Translation Elongation Factors (EEFs) are a large protein family that plays a central role in the peptides' biosynthesis during the elongation step of translation. This family counts different proteins and their isoforms and it is conventionally divided into two main subgroups: the Non-Alpha Eukaryotic Translation Elongation Factors (Non-alpha EEFs), that comprise the Eukaryotic Translation Elongation Factor 1 Beta 2 (eEF1B2), the Eukaryotic Translation Elongation Factor 1 Delta (eEF1D), the Eukaryotic Translation Elongation Factor 1 Gamma (eEF1G), and the Eukaryotic Translation Elongation Factor 1 Epsilon 1 (eEF1E1), including their isoforms, and the Alpha Eukaryotic Translation Elongation Factors (Alpha EEFs), that include the Eukaryotic Translation Elongation Factor 1 Alpha 1 (eEF1A1), Eukaryotic Translation Elongation Factor
1 Alpha 2 (EEF1A2), and their isoforms like the Prostate Tumor-Inducing Gene-1 (PTI-1), more recently renamed Eukaryotic Translation Elongation Factor 1-Alpha 1-Like 14 (EEF1A1L14), a more basic isoform of eEF1A1 (MBI-eEF1A), a cutaneous T-cell lymphoma antigen similar to eEF1A1 (HD-CL-08), and Cervical Cancer Suppressor (CCS-3).

The members of EEFs form a supramolecular complex named Eukaryotic Translation Elongation Factor-1 Macromolecular Complex (eEF1H) except for eEF1E1 that is a key component of another supramolecular complex, i.e. Multi-Aminoacyl-tRNA Synthetase Macromolecular Complex (MARS). eEF1H protein complex plays a central role in peptide elongation during eukaryotic protein biosynthesis, in particular for the delivery of aminoacyltRNAs to the ribosome mediated by the hydrolysis of GTP. In fact, during the elongation step of translation, the inactive GDP-bound form of eEF1A (eEF1A-GDP) is converted to its active GTP-bound form (eEF1A-GTP) by eEF1B2GDcomplex through GTP hydrolysis. Thus, eEF1B2GD-complex acts as a guanine nucleotide exchange factor (GEF) for the 


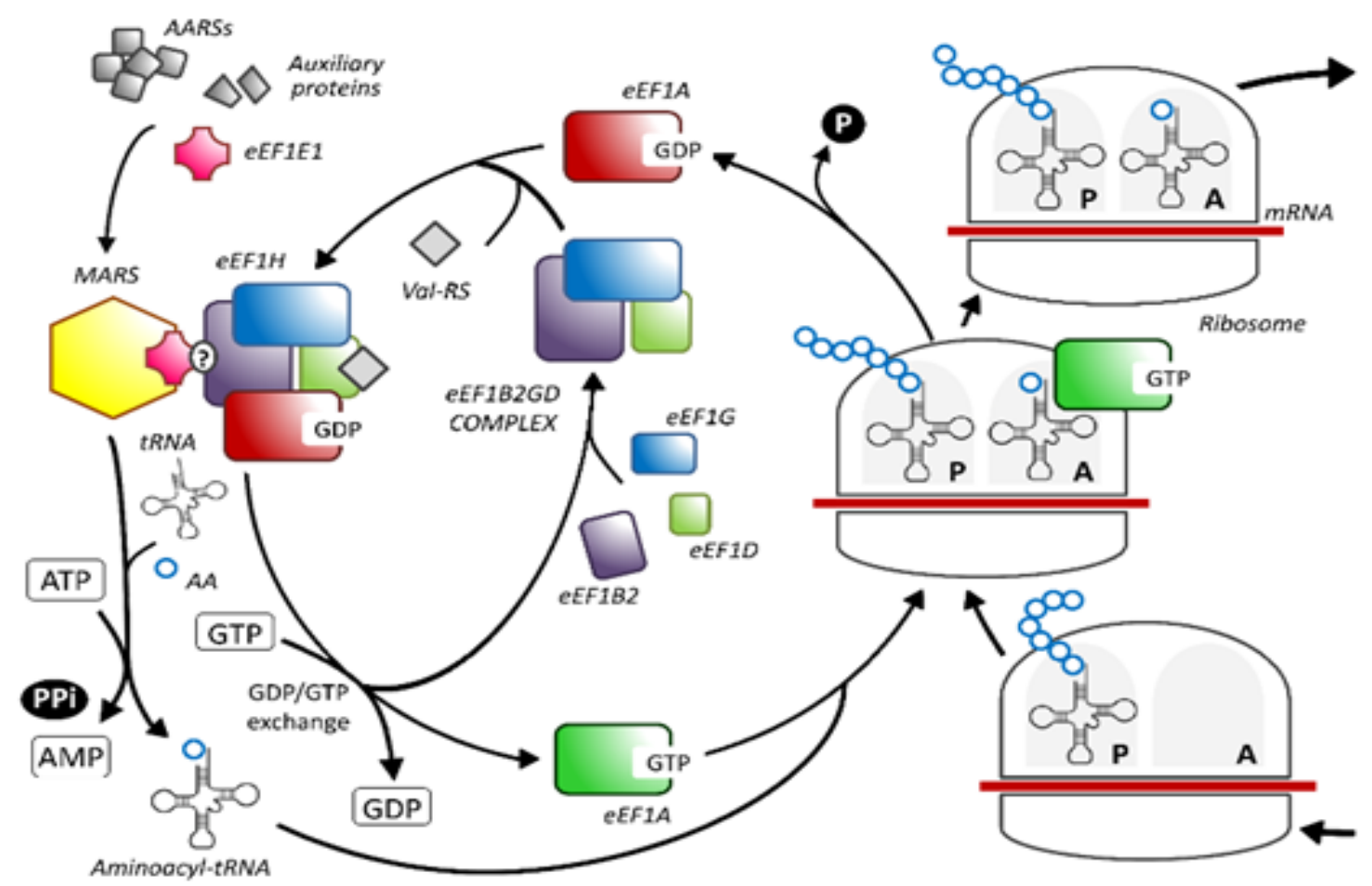

FIGURE 1: The elongation step of translation. The active form eEF1A, in complex with GTP, delivers an aminoacylated tRNA to the $A$ site of the ribosome. Following the proper codon-anticodon recognition the GTP is hydrolyzed and the inactive eEF1AGDP is released from the ribosome and then it is bound by the eEF1B2GD complex forming the macromolecular protein aggregate eEF1H. eEF1H is formed previously by the binding of three subunits: eEF1B2, eEF1G, and eEF1D. This complex promotes the exchange between GDP and GTP to regenerate the active form of eEF1A [1;4-8].

regeneration of eEF1A-GTP for the next elongation cycle [13] (Figure 1).

MARS protein complex, on the contrary, is formed by nine aminoacyl-tRNA synthetases (AARSs) and at least other three auxiliary non-synthetase protein components, [4-8] among which appears eEF1E1 [9-11]. eEF1E1 seems to contribute to the interaction and anchorage of MARS complex to $\mathrm{EF} 1 \mathrm{H}$ complex during the elongation step of translation [11,12]. The EEFs show also multiple noncanonical roles, called moonlighting roles, inside the cell [7] and they are all often altered in many kinds of cancer. Genomic rearrangements, gene amplification, novel fusion genes, point mutations, chimeric proteins, and altered expression levels were detected in many types of cancers and in other human diseases [13]. This wide spectrum of alterations for EEFs, common also for other genes and proteins, is frequently in cancer cells that are genetically more unstable respect to normal ones. Certainly, these abnormalities have repercussions on cellular biology and cellular behaviour in the various step of the malignancy transformation and progression. In the context of protein biosynthesis, the elongation step is doubtless accelerated and most likely loses fidelity and the control mechanisms fail or are less efficient. This can affect the worsening of the malignancy with direct and/or indirect repercussions on the progression of cancer, including the increase in invasiveness and, finally, in the metastasis. The purpose of this work is to briefly summarize the main studies in which the role of these proteins in tumor transformation has been identified in order to be able to start from here for further studies and analyzes.

\section{Non-Alpha Eukaryotic Translation Elongation Factors}

Non-alpha EEFs include most of the proteins that contribute to the translation elongation step in eukaryotes. These are eEF1B2, eEF1D, eEF1G, eEF1E1, and their isoforms. Here it will deal exclusively with the main proteins, excluding the isoforms because the studies on cancer are in their infancy for them. The expression levels for each member are shown in Table 1.

\section{EEF1B2}

EEF1B2, also known as EEF1B1 or eEF1 $\beta$ or eEF1B $\alpha$, was identified for the first time by Sanders and colleagues in 1991 [14]. It is the smallest subunit of EEF1H complex and among his moonlight roles are counted the control on the translation fidelity [2], the inhibition of protein 
synthesis in response to stressors, and the interaction with the cytoskeleton $[15,16]$. Gene expression for EEF1B2 was observed to be altered in many cancer types, in fact, it is frequently found overexpressed. Furthermore, EEF1B2 counts various kinds of genomic translocations and numerous fusion genes [1].

\section{EEF1D}

EEF1D, also known as eEF1Bdelta, was identified for the first time by Sanders and colleagues in 1993 [50]. Four isoforms were detected, produced by alternative splicing: isoform 1, also called eEF1DL, of 647 residues, and isoform 2 , of 281 amino acids, are the better known [51]. Its moonlight roles included its role as a transcriptional factor and its involvement in the stress response [51-53]. It is involved in a very large number of genomic translocations (and fusion genes) in different kinds of tumors and it was frequently found overexpressed. It was demonstrated that an increase in its expression level has an oncogenic potential with resulting in cell transformation [55]. Therefore, it is considered a cellular proto-oncogene [56].

\section{EEF1G}

EEF1G, also known as eEF1Y or eEF1By, was identified for the first time by Sanders and colleagues in 1992 [57]. There are known two isoforms produced by alternative splicing: isoform 1 (chosen as canonical), by 437 residues, and isoform 2, of 487 amino acids [58]. Its moonlight roles included the interaction with the cytoskeleton [27,59] and some nuclear and cytoplasmic proteins, such as RNA polymerase II [60], TNF receptor-associated protein 1 [61] and membrane-bound receptors [62]. In addition, it has mRNA binding properties $[60,63]$ and it is a positive regulator of the NF-kB signalling pathway [64]. It is involved in some genomic translocations (and fusion genes) in different kinds of tumors and it was frequently found overexpressed.

\section{EEF1E1}

EEF1E1, also known as p18 or AIMP3, was identified for the first time by Mao and colleagues in 1998 [65]. It is the smallest component of the MARS complex [66] and it has various moonlight roles inside the cell: it seems to play a role in mammalian embryonic development [67], in the DNA damage response [68], and in the degradation of mature Lamin A [69]. A great number of mutations in the genomic sequence and in the amino acid sequence for EEF1E1 were discovered in cancer cells as well as genomic translocations, novel fusion genes, and altered expression levels.

Table 1: List of EEFs and some of their most important isoforms with their expression levels in cancers.

\begin{tabular}{|c|c|c|c|c|c|c|c|c|c|c|}
\hline \multirow[b]{2}{*}{ Cancer Groups } & \multicolumn{4}{|c|}{ Non-alpha EEFs } & \multicolumn{6}{|l|}{ Alpha EEFs } \\
\hline & eEF1B2 & eEF1D & eEF1G & eEF1E1 & eEF1A1 & $\begin{array}{l}\text { MBI- } \\
\text { eEF1A }\end{array}$ & PTI-1 & CCS-3 & HD-CL-08 & eEF1A2 \\
\hline $\begin{array}{l}\text { Brain and central nervous } \\
\text { system cancers }\end{array}$ & High [13] & High [13] & High [13] & High [13] & High [13] & - & - & - & - & Low [13] \\
\hline $\begin{array}{l}\text { Head and neck squamous } \\
\text { cell carcinomas }\end{array}$ & Low [13] & High [13] & Low [13] & High [13] & High [37] & - & - & - & - & High [13] \\
\hline Melanomas & - & High [20] & High [26] & - & - & - & - & - & - & - \\
\hline Osteosarcomas & - & High [21] & - & - & - & - & - & - & - & - \\
\hline Thyroid cancer & - & - & - & - & - & - & - & - & - & - \\
\hline Breast cancers & High [17] & High [22] & High [27] & NO [13] & High [38] & - & - & - & - & High [45] \\
\hline Ovarian cancers & - & Low [23] & High [13] & High [13] & Low [13] & - & - & - & - & High [46] \\
\hline Uterine cancers & - & - & - & - & - & - & - & - & - & - \\
\hline Cervical cancers & - & - & High [28] & - & Low [39] & - & - & Low [43] & - & High [47] \\
\hline Esophageal carcinomas & High [18] & $\begin{array}{c}\text { High } \\
{[24 ; 25]}\end{array}$ & $\begin{array}{c}\text { High } \\
{[29 ; 30]}\end{array}$ & - & - & - & - & - & - & - \\
\hline Gastric cancers & High [19] & Low [13] & High [31] & Low $[34]$ & Low [13] & - & - & - & - & High [48] \\
\hline Colorectal cancers & NO [13] & High [13] & $\begin{array}{c}\text { High } \\
{[29 ; 32]} \\
\end{array}$ & Low [34;35] & NO [13] & - & - & - & - & NO [13] \\
\hline Liver cancers & - & High [13] & $\begin{array}{c}\text { High } \\
{[13 ; 33]}\end{array}$ & High [13] & High [40] & - & - & - & - & High [13] \\
\hline Pancreatic cancers & Low [13] & Low [13] & High [29] & Low [13] & Low [13] & - & - & - & - & High [13] \\
\hline Lung cancers & High [18] & High [18] & High [13] & High [13] & Low [13] & - & - & - & - & High [13] \\
\hline Kidney cancers & High [13] & High [13] & High [13] & Low [13] & High [13] & - & - & - & - & High [13] \\
\hline Bladder cancers & - & - & - & Low [36] & - & - & - & - & - & - \\
\hline Prostate cancers & NO [13] & High [13] & High [13] & High [13] & NO [13] & - & High [42] & - & - & High [50] \\
\hline $\begin{array}{l}\text { Lymphoma and other } \\
\text { blood cancers }\end{array}$ & High [13] & High [13] & High [13] & High [13] & - & High [41] & - & - & High [44] & - \\
\hline
\end{tabular}

Citation: Cristiano Luigi*. Translation Elongation Factors: are Useful Biomarkers in Cancer? Op Acc J Bio Sci \& Res 6(1)-2020. 
Alpha Eukaryotic Translation Elongation Factors

Alpha EEFs include all the isoforms for eEF1A. The main ones are eEF1A1 and eEF1A2. The minor isoforms discovered so far, all related to eEF1A1 alone, and reported here, are MBI-eEF1A, PTI-1, CCS-3, and HD-CL-08. The expression levels for each member are shown in Table 1.

\section{EEF1A1}

EEF1A1, or EEF1 $\alpha$ or EF-1 $\alpha$, is one of the most studied translation elongation factors. It is present in almost all cell types, with some exceptions, as it plays a key role in the translation process, i.e. in eukaryotes, it promotes the binding of aminoacyl-tRNA (aa-tRNA) to the 60 S subunit of the ribosome during the elongation process of the protein synthesis. To carry out its function it consumes a molecule of GTP, becoming inactive, and therefore needs to be recharged in its active form by the eEF1B2GD complex [2,3]. It has various moonlight functions, including cytoskeleton remodelling [70], promotion of misfolded protein degradation [71], control of the cell cycle [72], and the promotion of apoptosis [72]. EEF1A1 is often amplified and overexpressed in cancers [72]. This is related not only to its key role in protein synthesis but also to its many moonlight functions.

\section{MBI-eEF1A}

A more basic isoform of eEF1A1, alias MBI-eEF1A, was identified for the first time by Dapas and colleagues [41] in human haematopoietic cancer cell lines. This finding opens the possibility that also the post-translation modifications of eEF1A1 could be related to cancer development and/or progression and should be deeply studied [73].

PTI-1

PTI-1 was identified for the first time by Shen and colleagues in 1995 [74] and it shows similarities to eEF1A from whose amino acid sequence it differs for having lost 67 amino acids at the $\mathrm{N}$-terminal region. Initially considered a specific oncogene for prostate cancer, it later turned out to be unrelated but instead to be due to the infection of the cells by some species of bacteria belonging to the genus Mycoplasma, in particular Mycoplasma hyorhinis [75]. The exact role of PTI-1 is unknown but it has been suggested that it might reduce translational fidelity and so concur or bring to tumorigenesis [76].

\section{CCS-3}

CCS-3 was identified for the first time by Rho and colleagues in 2006 [43] and it shows similarities to eEF1A from whose amino acid sequence it differs for having lost 101 amino acids at the $\mathrm{N}$-terminal region. Its expression level is found to be very low to undetectable in human cervical cancer cells while is it higher in normal human cell lines. The functions of CCS-3 are still poorly understood, however from the studies carried out to date it seems that it may play a role as a transcriptional repressor $[43,77]$. Furthermore, low levels of its expression appear to prevent apoptosis so it could have also an anti-tumor activity [43].

\section{HD-CL-08}

It was discovered that a cutaneous T-cell lymphoma antigen, named HD-CL-08, shows high sequence homology with eEF1A1, but it lacks 77 amino acids in the $\mathrm{NH} 2$-terminal portion $[44,78]$.

\section{EEF1A2}

EEF1A2 is analogous to EEF1A1 and its expression is normally found only in some tissues, where it completely replaces EEF1A1, i.e. adult brain, heart, and skeletal muscle [79]. It is not expressed in other tissues under physiological conditions. The study of the role of EEF1A2 in the tumor transformation process has been conducted in many tumors, but the most characterizing researches have been carried out in ovarian and breast cancers. EEF1A2, in fact, is considered to be a putative oncogene in ovarian cancer [46]. Like EEF1A1, EEF1A2 is also highly expressed in many cancer types and its amplification is related to a poor clinical prognosis and an increase in tumor aggressiveness [72].

\section{Conclusion}

The family of The Eukaryotic Translation Elongation Factors has been studied for over thirty years and although data on expression levels are controversial among the studies, the large number of research and publications in the literature suggests that EEFs participate actively in tumorigenesis and so they may possibly useful biomarkers for human cancers. What needs to be clarified and better defined in an incontrovertible way is in which phase of the evolution of cancer they can make the greatest contribution and have the greatest role, i.e. being able to use them as diagnostic, prognostic and progression markers, but not only. They should be studied and evaluated also as indicators for the risk assessment, screening, differential diagnosis, prediction of response to treatment, and monitoring of metastases.

\section{Conflict of Interest}

The author declares that there is no conflict of interest

\section{Acknowledgements}

Funding sources: this research did not receive any specific grant from funding agencies in the public, 
commercial, or not-for-profit sectors.

\section{Abbreviations:}

Alpha EEFs: Alpha Eukaryotic Translation Elongation Factors; CCS-3: Cervical Cancer Suppressor 3; EEFs: Eukaryotic Translation Elongation Factors; eEF1A1: eukaryotic Translation Elongation Factor 1 alpha 1; eEF1A1L14: Eukaryotic Translation Elongation Factor 1-alpha 1-like 14; eEF1A2: eukaryotic translation Elongation Factor 1 alpha 2; eEF1B2: eukaryotic translation Elongation Factor 1 beta 2;eEF1D: eukaryotic translation Elongation Factor 1 delta; eEF1G: eukaryotic Translation Elongation Factor 1 gamma; eEF1E1: eukaryotic translation Elongation Factor 1 epsilon 1; eEF1H: eukaryotic translation Elongation Factor-1 macromolecular complex; HD-CL-08: cutaneous T-cell lymphoma antigen (similar to eEF1A1); MARS: Multiaminoacyl-tRNA synthetase macromolecular complex; MBI-eEF1A: More Basic isoform of eEF1A; Non-alpha EEFs: not-alpha eukaryotic translation Elongation Factors;PTI-1: Prostate Tumor-inducing gene-1.

\section{References}

1. Cristiano L (2020) EEF1B2 (eukaryotic translation elongation factor 1 beta 2). Atlas Genet Cytogenet Oncol Haematol 24(9): 338-345.

2. Le Sourd F, Boulben S, Le Bouffant R, Cormier P, Morales J, et al. (2006) eEF1B: At the dawn of the 21st century. Biochim Biophys Acta 1759(1-2): 13-31.

3. Browne GJ, Proud CG (2002) Regulation of peptide-chain elongation in mammalian cells. Eur J Biochem 269(22): 5360-5368.

4. Poruri K (2020) Aminoacyl-tRNA Synthetases. Mater Methods 10: 2866.

5. Pang YL, Poruri K, Martinis S (2014) tRNA synthetase: tRNA aminoacylation and beyond. Wiley Interdiscip Rev RNA 5(4): 461-80.

6. Li D, Wei T, Abbott CM, Harrich D (2013) The unexpected roles of eukaryotic translation elongation factors in RNA virus replication and pathogenesis. Microbiol Mol Biol Rev $77(2): 253-266$.

7. Ejiri S (2002) Moonlighting functions of polypeptide elongation factor 1: from actin bundling to zinc finger protein R1-associated nuclear localization. Biosci Biotechnol Biochem 66(1): 1-21.

8. Riis B, Rattan SI, Clark BF, Merrick WC (1990) Eukaryotic protein elongation factors. Trends Biochem Sci 15(11): 420-424.

9. Cho HY, Maeng SJ, Cho HJ, Choi YS, Chung JM, et al. (2015) Assembly of Multi-tRNA Synthetase Complex via Heterotetrameric Glutathione Transferase-homology Domains. J Biol Chem 290(49): 29313-29328.

10. Shalak V, Guigou L, Kaminska M, Wautier MP, Wautier JL, et al. (2007) Characterization of p43(ARF), a derivative of the p43 component of multiaminoacyl-tRNA synthetase complex released during apoptosis. J Biol Chem 282(15): 10935-10943.
11. Quevillon S, Mirande M (1996) The p18 component of the multisynthetase complex shares a protein motif with the beta and gamma subunits of eukaryotic elongation factor 1. FEBS Lett 395(1): 63-67.

12. Deineko VV (2008) On ARS-interacting multifunctional protein p18. Nat Prec.

13. Hassan MK, Kumar D, Naik M, Dixit M (2018) The expression profile and prognostic significance of eukaryotic translation elongation factors in different cancers. PLoS One 13(1): e0191377.

14. Sanders J, Maassen JA, Amons R, Möller W (1991) Nucleotide sequence of human elongation factor-1 beta cDNA. Nucleic Acids Res 19(16): 4551.

15. Khudhair N, Cuiping Y, KhalidA, Gao X (2014) Role of eEF1B subunits in regulation phosphorylation and some functions. J Genet Environ Resour Conserv 2(3): 270-282.

16. Sasikumar AN, Perez WB, Kinzy TG (2012) The many roles of the eukaryotic elongation factor 1 complex. Wiley Interdiscip Rev RNA 3(4): 543-555.

17. Al-Maghrebi M, Anim JT, Olalu AA (2005) Up-regulation of eukaryotic elongation factor-1 subunits in breast carcinoma. Anticancer Res 25(3c): 2573-2577.

18. Veremieva M, Kapustian L, Khoruzhenko A, Zakharychev V, Negrutskii B et al. (2014) Independent overexpression of the subunits of translation elongation factor complex eEF1H in human lung cancer. BMC Cancer 14: 913.

19. Jia L, Yang T, Gu X, Zhao W, Tang Q, et al (2019) Translation elongation factor eEF1B $\alpha$ is identified as a novel prognostic marker of gastric cancer. Int J Biol Macromol 126: 345-351.

20. Sinha P, Kohl S, Fischer J, Hütter G, Kern M, et al. (2000) Identification of novel proteins associated with the development of chemoresistance in malignant melanoma using two-dimensional electrophoresis. Electrophoresis 21(14): 3048-3057.

21. Cheng DD, Li SJ, Zhu B, Zhou SM, Yang QC (2018) EEF1D overexpression promotes osteosarcoma cell proliferation by facilitating Akt-mTOR and Akt-bad signaling. J Exp Clin Cancer Res 37(1): 50.

22. Flores IL, Kawahara R, Miguel MC, Granato DC, Domingues RR, et al. (2016) EEF1D modulates proliferation and epithelial-mesenchymal transition in oral squamous cell carcinoma. Clin Sci (Lond) 130(10): 785-799.

23. Siavoshi A, Taghizadeh M, Dookhe E, Piran M, Saliani M, et al. (2020) Network Analysis of Differential Gene Expression to Identify Hub Genes in Ovarian Cancer. J Cell Mol Res 12(1): 1-9.

24. Veremieva M, Khoruzhenko A, Zaicev S, Negrutskii B, El'skaya A (2011) Unbalanced expression of the translation complex eEF1 subunits in human cardioesophageal carcinoma. Eur J Clin Invest 41(3): 269-276.

25. Ogawa K, Utsunomiya T, Mimori K, Tanaka Y, Tanaka F, et al. (2004) Clinical significance of elongation factor-1 delta mRNA expression in oesophageal carcinoma. Br J Cancer 91(2): 282-286.

26. Gan Y, Li N, Zou G, Xin Y, Guan J (2018) Identification of cancer subtypes from single-cell RNA-seq data using a consensus clustering method. BMC Med Genomics 11(Suppl 6): 117.

27. Coumans JV, Gau D, Poljak A, Wasinger V, Roy P, et al. (2014) 
Green fluorescent protein expression triggers proteome changes in breast cancer cells. Exp Cell Res 320(1): 33-45.

28. Shadeo A, Chari R, Lonergan KM, Pusic A, Miller D, et al. (2008) Up regulation in gene expression of chromatin remodelling factors in cervical intraepithelial neoplasia. BMC Genomics 9: 64.

29. Frazier ML, Inamdar N, Alvula S, Wu E, Kim YH (1998) Few point mutations in elongation factor-1gamma gene in gastrointestinal carcinoma. Mol Carcinog 22(1): 9-15.

30. Mimori K, Mori M, Tanaka S, Akiyoshi T, Sugimachi K (1995) The overexpression of elongation factor 1 gamma mRNA in gastric carcinoma. Cancer 75(6 Suppl): 14461449.

31. Takenawa H, Kurosaki M, Enomoto N, Miyasaka Y, Kanazawa N, et al. (2004) Differential gene-expression profiles associated with gastric adenoma. Br J Cancer 90(1): 216-223.

32. Ender B, Lynch P, Kim YH, Inamdar NV, Cleary KR, et al. (1993) Overexpression of an elongation factor-1 gammahybridizing RNA in colorectal adenomas. Mol Carcinog 7(1): 18-20.

33. Wang R, Cai Y, Zhang B, Wu Z (2018) A 16-gene expression signature to distinguish stage I from stage II lung squamous carcinoma. Int J Mol Med 41(3):1377-1384.

34. Kim SS, Hur SY, Kim YR, Yoo NJ, Lee SH (2011) Expression of AIMP1, 2 and 3, the scaffolds for the multi-tRNA synthetase complex, is downregulated in gastric and colorectal cancer. Tumori 97(3): 380-385.

35. Chen J, Liu S, Hu X (2018) Long non-coding RNAs: crucial regulators of gastrointestinal cancer cell proliferation. Cell Death Discov 4: 50.

36. Gurung PM, Veerakumarasivam A, Williamson M, Counsell N, Douglas J, et al. (2015) Loss of expression of the tumour suppressor gene AIMP3 predicts survival following radiotherapy in muscle-invasive bladder cancer. Int J Cancer 136(3): 709-720.

37. Johnsson A, Zeelenberg I, Min Y, Hilinski J, Berry C, et al. (2000) Identification of genes differentially expressed in association with acquired cisplatin resistance. Br J Cancer 83(8): 1047-1054.

38. Joseph P, O'Kernick C, Othumpangat S, Lei Y, Yuan B, et al. (2004) Expression profile of eukaryotic translation factors in human cancer tissues and cell lines. Mol Carcinog 40: 171-179.

39. Zhao Q, He Y, Wang X-L, Zhang Y-X, Wu Y-M (2015) Differentially expressed proteins among normal cervix, cervical intraepithelial neoplasia and cervical squamous cell carcinoma. Clin Transl Oncol 17: 620-631.

40. Huang J, Zheng C, Shao J, Chen L, Liu X, et al. (2017) Overexpression of eEF1A1 regulates G1-phase progression to promote HCC proliferation through the STAT1-cyclin D1 pathway. Biochem Biophys Res Commun 494(3-4): 542549.

41. Dapas B, Tell G, Scaloni A, Pines A, Ferrara L, et al. (2003) Identification of different isoforms of eEF1A in the nuclear fraction of human T-lymphoblastic cancer cell line specifically binding to aptameric cytotoxic GT oligomers. Eur J Biochem 270(15): 3251-3262.

42. Sun Y, Lin J, Katz AE, Fisher PB (1997) Human Prostatic
Carcinoma Oncogene PTI-1 Is Expressed in Human Tumor Cell Lines and Prostate Carcinoma Patient Blood Samples. Cancer Res 57(1): 18-23.

43. Rho SB, Park YG, Park K, Lee SH, Lee JH (2006) A novel cervical cancer suppressor 3 (CCS-3) interacts with the BTB domain of PLZF and inhibits the cell growth by inducing apoptosis. FEBS Lett 580(17): 4073-4080.

44. Hartmann TB, Thiel D, Dummer R, Schadendorf D, Eichmuller S (2004) SEREX identification of a new tumourassociated antigens in cutaneous T-cell lymphoma. $\mathrm{Br} \mathrm{J}$ Dermatol 150: 252-258.

45. Tomlinson VA, Newbery HJ, Wray NR, Jackson J, Larionov A, et al. (2005) Translation elongation factor eEF1A2 is a potential oncoprotein that is overexpressed in two-thirds of breast tumours. BMC Cancer 5: 113.

46. Pinke DE, Kalloger SE, Francetic T, Huntsman DG, Lee JM (2008) The prognostic significance of elongation factor eEF1A2 in ovarian cancer. Gynecol Oncol 108(3): 561-568.

47. Pan Z, Chen S, Pan X, Wang Z, Han H, etal. (2010) Differential gene expression identified in Uigur women cervical squamous cell carcinoma by suppression subtractive hybridization. Neoplasma 57(2): 123-128.

48. Yang S, Lu M, Chen Y, Meng D, Sun R, et al. (2015) Overexpression of eukaryotic elongation factor 1 alpha-2 is associated with poorer prognosis in patients with gastric cancer. J Cancer Res Clin Oncol 141(7): 1265-1275.

49. Scaggiante B, Dapas B, Bonin S, Grassi M, Zennaro C et al. (2012) Dissecting the expression of EEF1A1/2 genes in human prostate cancer cells: the potential of EEF1A2 as a hallmark for prostate transformation and progression. $\mathrm{Br}$ J Cancer 106: 166-173.

50. Sanders J, Raggiaschi R, Morales J, Moller W (1993) The human leucine zipper-containing guanine-nucleotide exchange protein elongation factor-1 delta. Biochim Biophys Acta 1174: 87-90.

51. Cristiano L (2020) EEF1D (eukaryotic translation elongation factor 1 delta). Atlas Genet Cytogenet Oncol Haematol 24(3):117-

52. Kaitsuka T, Matsushita M (2015) Regulation of Translation Factor EEF1D Gene Function by Alternative Splicing. Int J Mol Sci 16: 3970-3979.

53. Hensen SM, Heldens L, van Genesen ST, Pruijn GJ, Lubsen NH (2013) A delayed antioxidant response in heatstressed cells expressing a non-DNA binding HSF1 mutant. Cell Stress Chaperones 18(4): 455-473.

54. Kaitsuka T, Tomizawa K, Matsushita M (2011) Transformation of eEF1B $\delta$ into heat-shock response transcription factor by alternative splicing. EMBO Rep 12(7): 673-681.

55. Lei YX, Chen JK, Wu ZL (2002) Blocking the translation elongation factor- 1 delta with its antisense mRNA results in a significant reversal of its oncogenic potential. Teratog Carcinog Mutagen 22(5): 377-383.

56. Joseph P, Lei YX, Whong WZ, Ong TM (2002) Oncogenic potential of mouse translation elongation factor-1 delta, a novel cadmium-responsive proto-oncogene. J Biol Chem 277(8): 6131-6136.

57. Sanders J, Maassen JA, Moller W (1992) Elongation factor-1 messenger-RNA levels in cultured cells are high 
compared to tissue and are not drastically affected further by oncogenic transformation. Nucleic Acids Res 20: 5907 5910.

58. Cristiano L (2020) EEF1G (Eukaryotic translation elongation factor 1 gamma). Atlas Genet Cytogenet Oncol Haematol 24(2): 58-68.

59. Kim S, Kellner J, Lee CH, Coulombe PA (2007) Interaction between the keratin cytoskeleton and eEF1Bgamma affects protein synthesis in epithelial cells. Nat Struct Mol Biol 14(10): 982-983.

60. Corbi N, Batassa EM, Pisani C, Onori A, Di Certo MG, et al. (2010) The eEF1 $\gamma$ subunit contacts RNA polymerase II and binds vimentin promoter region. PLoS One 5(12): e14481.

61. Matassa DS, Amoroso MR, Agliarulo I, Maddalena F, Sisinni L, et al. (2013) Translational control in the stress adaptive response of cancer cells: a novel role for the heat shock protein TRAP1. Cell Death Dis 4: e851.

62. Cho DI, Oak MH, Yang HJ, Choi HK, Janssen GM, et al. (2003) Direct and biochemical interaction between dopamine D3 receptor and elongation factor-1Bbetagamma. Life Sci 73(23): 2991-3004.

63. Pisani C, Onori A, Gabanella F, Delle Monache F, Borreca A, et al. (2016) eEF1B $\gamma$ binds the Che- 1 and TP53 gene promoters and their transcripts. J Exp Clin Cancer Res 35(1): 146.

64. Liu D, Sheng C, Gao S, Jiang W, Li J, et al. (2014) eEF1B is a positive regulator of NF-B signaling pathway. Biochem Biophys Res Commun 446(2): 523-528.

65. Mao M, Fu G, Wu JS, Zhang QH, Zhou J, et al. (1998) Identification of genes expressed in human CD34(+) hematopoietic stem/progenitor cells by expressed sequence tags and efficient full-length cDNA cloning. Proc Natl Acad Sci USA 95(14): 8175-8180.

66. Cristiano L (2020) EEF1E1 (eukaryotic translation elongation factor 1 epsilon 1). Atlas Genet Cytogenet Oncol Haematol 24(11): 387-395.

67. Fowles LF, Bennetts JS, Berkman JL, Williams E, Koopman P, et al. (2003) Genomic screen for genes involved in mammalian craniofacial development. Genesis 35(2): 7387.

68. Park BJ, Kang JW, Lee SW, Choi SJ, Shin YK, et al. (2005) The haploinsufficient tumor suppressor p18 upregulates p53 via interactions with ATM/ATR. Cell 120(2): 209-221.

69. Tao Y, Fang P, Kim S, Guo M, Young NL, et al. (2017) Mapping the contact surfaces in the Lamin A:AIMP3 complex by hydrogen/deuterium exchange FT-ICR mass spectrometry. PLoS One 12(8): e0181869.

70. Condeelis J (1995) Elongation factor $1 \alpha$, translation and the cytoskeleton. Trends Biochem Sci 20: 169-170.

71. Gonen H, Smith CE, Siegel NR, Kahana C, Merrick WC, et al. (1994) Protein synthesis elongation factor EF-1 alpha is essential for ubiquitin-dependent degradation of certain $\mathrm{N}$ alpha-acetylated proteins and may be substituted for by the bacterial elongation factor EF-Tu. Proc Natl Acad Sci USA 91(16): 7648-7652.

72. Thornton S, Anand N, Purcell D, Lee J (2003) Not just for housekeeping: protein initiation and elongation factors in cell growth and tumorigenesis. J Mol Med 81(9): 536-548.

73. Scaggiante B, Dapas B, Pozzato G, Grassi G (2013) The more basic isoform of eEF1A relates to tumour cell phenotype and is modulated by hyper-proliferative/ differentiating stimuli in normal lymphocytes and CCRFCEM Tlymphoblasts. Hematol Oncol 31(2): 110-116.

74. Shen R, Su ZZ, Olsson CA, Fisher PB (1995) Identification of the human prostatic carcinoma oncogene PTI-1 by rapid expression cloning and differential RNA display. Proc Natl Acad Sci USA 92(15): 6778-6782.

75. Scaggiante B, Bonin S, Cristiano L, Siracusano S, Stanta G, et al. (2008) Prostate Tumor-Inducing Gene-1 Analysis in Human Prostate Cancer Cells and Tissue in Relation to Mycoplasma Infection. Cancer Invest 26(8): 800-808.

76. Gopalkrishnan RV, Su Z-Z, Goldstein NI, Fisher PB (1999) Translational infidelity and human cancer: role of the PTI1 oncogene. Int J Biochem Cell Biol 31:151-162.

77. Choi WI, Kim Y, Kim Y, Yu MY, Park J, et al. (2009) Eukaryotic translation initiator protein $1 \mathrm{~A}$ isoform, CCS3 , enhances the transcriptional repression of p21CIP1 by proto-oncogene FBI-1 (Pokemon/ZBTB7A). Cell Physiol Biochem 23(4-6): 359-370.

78. Frum R, Busby SA, Ramamoorthy M, Deb S, Shabanowitz J, et al. (2007) HDM2-Binding Partners: Interaction with Translation Elongation Factor EF1 $\alpha$. J Proteome Res 6(4): 1410-1417.

79. Knudsen SM, Frydenberg J, Clark BF, Leffers H (1993) Tissue-dependent variation in the expression of elongation factor-1 alpha isoforms: isolation and characterization of a cDNA encoding a novel variant of human elongation-factor 1 alpha. Eur J Biochem 215(3): 549-554.

*Corresponding author: Cristiano Luigi, Email: luigicristiano@libero.it

Next Submission with BGSR follows:

- Rapid Peer Review

- Reprints for Original Copy

- E-Prints Availability

- Below URL for auxiliary Submission Link: https://biogenericpublishers.com/submit-manuscript/ 